faculty is making proposals to strengthen it and bind it ever more closely to its parent body, the Royal College of Surgeons.

DEREK SEEL

Faculty of Dental Surgery

Roval College of Surgeons of England,

London WC2A $3 \mathrm{PN}$

1 Delamothe T. Hunterian Institute and dental research. Br. Med 7 1989:299:757. 23 September

\title{
Mumps, measles, and rubella vaccination and encephalitis
}

SIR,-Dr Suzanne Crowley and colleagues describe the onset of encephalitis in a 14 month old girl 27 days after she was given mumps, measles, and rubella vaccine. In this case it should be emphasised that there is no proof that the encephalitis was due to the mumps component of the vaccine. The fourfold rise in mumps $S$ titre could simply reflect successful immunisation. In Canada, where there have been several reports of meningitis arising within four weeks of giving mumps, measles, and rubella vaccine, mumps virus was isolated from the cerebrospinal fluid in all cases, although it was not possible to prove the origin of the viruses

After over one million doses of mumps, measles, and rubella vaccine it would be surprising if the occasional neurological reaction did not occur, but it would be a pity if current initiatives to improve the protection of British children from measles, mumps, and rubella were to be affected adversely by the publication of such a speculative case report. Nevertheless, it is most important that such cases are fully documented and reported on the "yellow card" system to the Committee on Safety of Medicines so that the benefits and risks of new vaccines can be kept in perspective. Experience to date indicates that the frequency of central nervous system complications after mumps vaccination is lower than the background incidence in the normal population. It is also worth emphasising that this patient and the Canadian patients recovered completely from the encephalitis.

A G M CAMPBELL.

Chairman

Joint Committee on

Vaccination and Immunisation

Department of Child Health

University of Aberdeen,

Aberdeen $A B 92 Z D$

1 Crowley S, Al-Jawad ST, Kovar IZ. Mumps, measles and rubella vaccination and encephalitis. Br Med 7 1989;299:660. September

2 Hockin JC. Mumps meningitis, possiblv vaccine related Ontario. Canada Diseases Weekly Report 1988;14:209-11.

\section{Follicular stimulation: is it safe?}

SIR,-Drs S Fishel and P Jackson raise the question of causality of follicular stimulation in the genesis of ovarian cancer.' Although they emphasise that there is no direct evidence to support their hypothesis, their discussion is incomplete.

Ovarian cancer is a common malignancy in women. ${ }^{2}$ Particularly, women with low parity or infertility, or both, are at a higher risk of developing ovarian cancer. Nulligravidas present twice the risk of developing malignant ovarian tumours than women who have been pregnant." A silent ovarian carcinoma was found in six out of 571 patients undergoing microsurgery for infertility, compared with only one of 5806 patients undergoing non-specific abdominal surgery (a crude relative risk of $62,95 \%$ confidence interval 7 to 514). ${ }^{+}$This sampling bias should be taken into account when analysing the three case reports of ovarian cancer during induction of ovulation quoted by Drs Fishel and Jackson.

The question was raised as to whether pharmacological follicular stimulation might modify the prevalence of ovarian carcinomas. In animals, experimental ovarian tumours generated by continuous high gonadotrophin levels originate from the stromal cells of the ovary'; they therefore are not a relevant model of human ovarian neoplasms, which are mostly of epithelial origin." Luteinising hormone receptors were found in only a quarter of human malignant ovarian cancers, and, moreover, these cancers contained fewer luteinising hormone receptors than did normal ovarian tissue, which might represent normal ovarian tissue trapped between cancer cells. ${ }^{2} \mathrm{Al}-$ though it was functional, the adenylate-cyclase system of human epithelial ovarian cancer cells could not be stimulated by either follicle stimulating hormone or luteinising hormone, indicating that ovarian cancers were not target tissues for gonadotrophins.

Oestrogen secretion is increased by gonadotrophins, but there is much evidence to indicate that steroids have a protective action against ovarian cancer. ${ }^{2}$ Several epidemiological studies do not support a hypothesis of ovarian tumours induced by gonadotrophin. ${ }^{26}$ Mortality due to ovarian cancer levels off after the menopause, at a time when gonadotrophin levels are high and when mortality from epithelial cancers not dependent on hormones continues to increase. 6 "

Therefore, several arguments indicate that gonadotrophins are unlikely to cause ovarian malignancies. As it cannot, however, be totally ruled out that follicular stimulation might activate certain types of pre-existing ovarian cancers, and in view of the relatively high risk for infertile women of spontaneously presenting with ovarian cancer, the need for careful clinical evaluation with ultrasonic ${ }^{9}$ or other modern imaging techniques before and during medical treatment of infertility must be emphasised.

K BESSEGHIR A ESHKOI

\section{Ares-Serono,}

CH 1202 Geneva,

Switzerland

P BRINSDEN

Bourn Hallam Infertility Centre, R G EDWARDS

Bourn,

Cambridge CB3 7TR

1 Fishel S, Jackson P. Follicular stimulation for high tech pregnancies: are we playing it safe? Br Med f 1989;299:309-11. (29 July

2 Heintz AP, Hacker NF, Lagasse LD. Epidemiology and etiology of ovarian cancer: a review. Obstet Gynecol 1985;66:127-35.

3 Scott JS. How to induce ovarian cancer: and how not to. Br.Med $\mathcal{f}$ 1984:289:781.

4 Lais CW, Williams TJ, Gaffey TA. Prevalence of ovarian cancer found at the time of infertility microsurgery. Fertil Steri 1988:49:551-3.

5 Cramer DW, Welch WR. Determinants of ovarian cancer risk. II. Inferences regarding pathogenesis. f $N C I$ 1983;71:717-21. 6 Mohle J, Whittemore A, Pike M, Darby S. Gonadotrophins and ovarian cancer risk. $7 \mathrm{NCl}$ 1985;75:178-80.

Rajaniemi H, Kauppila A, Rönnberg L, Selander K, Pystynen P. LH(hCG) receptor in benign and malignant tumors of human ovary. Acta Obstet Gynecol Scand [S uppl] 1981;101:83-6.

8 Graves PE, Surwit EA, Davis JR, Stouffer RL. Adenylate cyclase in human ovarian cells: sensitivity to gonadotrophins and nonhormonal activators. Am f Obstet Gynecol 1985:153: $877-82$.

9 Rodriguez MH, Platt LD, Medeavis AL, Lacarra M, Lobo $\mathrm{RA}$. The use of transvaginal sonography for evaluation of postmenopausal ovarian size and morphology. Am f Obstet postmenopausal ovarian

SIR, - Drs R Kulkarni and J M McGarry' state that the warning of Drs S Fishel and P Jackson ${ }^{2}$ about the possible dangers of superovulation for assisted conception is correct and describe a single case of gynaecological tumour following treatment with antioestrogens. Four other case reports of either ovarian or breast cancer in association with ovarian follicular stimulation have been published, ${ }^{3.6}$ but though the effect of such treatment on the inci- dence of such cancers must be carefully considered we think that the question can be answered only by prospective studies with carefully selected control groups rather than by a steady stream of case reports. Even if an association were found it would not necessarily indicate an effect of ovarian stimulation; indeed, a more likely explanation would be that an underlying ovulatory disorder or simply the absence of pregnancy predisposes to gynaecological cancer. There are data showing that women with anovulatory infertility have five to six times the risk of developing premenopausal and postmenopausal breast cancer. ${ }^{7}$ In addition, polycystic ovarian disease, the commonest cause of anovulation, ${ }^{4}$ increases the risk of endometrial cancer, "and Babaknia and colleagues found an excess of ovarian neoplasms in 181 consecutive patients with SteinLeventhal syndrome attending their clinic, many of whom presented before the advent of treatment to induce ovulation.

Clearly, breast and pelvic tumours will in any case arise during or shortly after ovarian stimulation as a matter of chance alone. If follicular stimulation were to predispose to epithelial malig. nancies of the ovary, endometrium, and breast the increasing and widespread use of such treatment over the past 20 years would have been expected to generate far more than the small number of case reports that have been made. The reporting of single cases or small series tends to create false impressions and may lead to unnecessary anxiety for patients and doctors alike.

Any reluctance to prescribe such treatments as the result of such fears would deprive many women not only of the joys of motherhood but of the apparent protection that pregnancy and lactation give against developing malignant breast tumours."

ROBERT FOX PETER WARDLE

Department of Obstetrics and Gynaecology, Bristol Maternity Hospital. Bristol BS2 8EG

1 Kulkarni R, McGarry JM. Follicular stimulation and ovaria cancer. Br.Med f 1989;299:740. (16 September.

2 Fishel S, Jackson P. Follicular stimulation for high tech pregnancies: are we playing it safe? Br Med $\mathcal{F}$ 1989;299. 309-11. (29 July

3 Atlas M, Merczer J. Massive hyperstimulation and borderline carcinoma of the ovary. A possible association. Acta Obstet Gynecol Scand 1982:61:261-3.

+ Bamford IM, Steele SJ. Uterine and ovarian carcinoma in patient receiving gonadotrophin therapy-case report. Brf Obstet (jynaecol 1982;89:962-4.

5 Carter ME, Joyce DN. Ovarian carcinoma in a patien hyperstimulated by gonadotrophin therapy for in-vitro fertilication: a case report. I In Vitro Fert Embryo Transfer 1987;4:126-8.

6 Laing RW, Glaser MG, Barrett GS. A case report of breast carcinoma in association with in-vitro fertilisation. $\mathcal{J} R$ So Med 1989;82:503

7 Cowan LD, Gordis L, Tonascia JA, et al. Breast cance incidence in women with a history of progesterone deficiency. Am f Epidemiol 1981;114:209-17.

8 Coulan $\mathrm{CB}$, Annergers JF. Chronic anovulation may increase postmenopausal breast cancer risk. FAMA 1983;249:445-6.

9 Hull MGR. Epidemiology of infertility and polycystic ovarian disease: endocrinological and demographic sudies. Gynecology and Endocrinology 1988;1:235-42.

10 Adams J, Polson DW, Franks S. The prevalence of polycystic ovaries in women with anovulation and idiopathic hirsutism. ovaries in women with an
$B r$ Med 7 1986;293:355-9.

11 Chamlian DL, Taylor HB. Endometrial hyperplasia in young women. Obstet Gynecol 1970;36:659-66.

12 Babaknia A, Calfopoulos P, Jones HW. The Stein-Leventhat syndrome and coincidental ovarian tumours. Obstet Gynecol 1976;47:223-4

13 Alderson M. Parity and breast cancer. Br Med J 1981;283 9-12.

\section{Abortion debate}

SIR,-Dr Tony Delamothe's summary of the abortion debate ${ }^{1}$ and $\mathrm{Mr}$ John M McGarry's earlier letter on the safety of therapeutic abortion ${ }^{2}$ prompt me to offer my 20 years' experience as a hospital chaplain and parish priest of the consequences of abortion

About $80 \%$ of people I see are those 